\title{
Does Anxiety Really Matters?
}

\author{
Ali Doğan \\ Azamat Akbarov \\ International Burch University, Sarajevo, Bosnia and Herzegovina \\ ali.dogan@zirve.edu.tr, azamat.akbarov@ibu.edu.ba
}

Doi:10.5901/mjss.2014.v5n9p681

\section{Abstract}

Researches show that exam anxiety is one of the negative factors having an effect on EFL. Experiments of EFL students and teachers also justifies these researches. With this study, the aim is to define the exam anxiety levels of Turkish EFL students and find out the reasons and results of this problem. It is also aimed to help our education system with the study on Turkish EFL students' exam anxiety. In the study, exam anxiety scale has been applied to the students in the Foreign Language School of a private university, and the collected data has been analyzed. The study concluded with two main results, the first one of which is that EFL Turkish students have higher exam anxiety levels. The second result is that higher level of exam anxiety affects the language learning process of EFL Turkish students negatively. With the end of this study, conducting new researches and making new arrangements about lowering the exam anxiety of EFL Turkish students are suggested.

Keywords: Learning, Test anxiety, English as Foreign Language

\section{Introduction}

\subsection{What is anxiety?}

Anxiety as an affective state is defined as an uncomfortable emotional state in which one perceives danger, feels powerless, and experiences tension in the face an expected danger (Blau, 1955). It can be classified into three types. Trait anxiety, a more permanent disposition to be anxious (Scovel, 1978), is viewed as an aspect of personality. State anxiety is an apprehension experienced at a particular moment in time as a response to a definite situation (Spielberger, 1983). Finally, the last of the three types, situation specific anxiety is related to apprehension unique to specific situations and events (Ellis, 1994).

\subsection{What is language (classroom) anxiety?}

Language anxiety is a distinct complex of self-perceptions, beliefs, feelings and behaviors related to classroom language learning arising from the uniqueness of the language learning process (Horwitz, Horwitz, \& Cope, 1986). Language anxiety falls under the category of situation specific anxiety. The results of the previously conducted studies regarding foreign language anxiety indicate those personal and impersonal anxieties, learners' beliefs about learning a foreign language, teachers' beliefs about teaching a foreign language, classroom procedures and testing are among the main sources of anxiety (Young, 1991). Furthermore, a review of the related literature reveals that the level of language course, language skills, motivation, proficiency, teachers, tests, and culture (Young, 1991) are other factors arousing anxiety.

At the end of the learning process, learners are usually expected to become proficient in several areas of the target language, such as pronunciation, grammar, vocabulary, discourse, and language skills. On the other hand, it is obvious that the learning of English as a foreign language is closely and directly related to the awareness about certain individual differences, such as the beliefs, attitudes, aptitudes, motivations and affective states of learners. Among these variables, particularly language anxiety as an individual difference is an affective state seriously impeding achievement in a foreign language (Gardner, 1985). Also it is stated that

Some learners expressed that they feel nervous and stressful when they can not speak English well and others maintained that they try to escape the situations which require speaking in front of others, either in the classroom or outside of the classroom (Aydogan et al., 2013). 


\subsection{What is test anxiety?}

Sarason (1984 in Oxford 1999) defines test anxiety as "the tendency to become alarmed about the consequences of inadequate performance on a test or other evaluation" (p.54). Test-anxious learners habitually put impractical demands on themselves and "feel that anything less than a perfect test performance is a failure" (Horwitz et al, 1986, p.128). Young (1991) claimed that test anxiety could affect foreign language learners with low levels of oral proficiency more than those with high levels of oral proficiency. On the other hand, it is believed that test anxiety would occur when learners had poor performances in the previous tests or evaluation situations. From those unhappy experiences, students would develop a negative stereotype about tests or quizzes and then have irrational perceptions in evaluation situations. Test-anxious learners habitually put impractical demands on themselves and "feel that anything less than a perfect test performance is a failure" (Cao, 2011, p.85).

The related literature on test anxiety in language learning point out that the factors that influence students' reactions to language tests are perceptions of test validity, time limit, test techniques, test format, length, testing environment and clarity of test instructions (Young, 1991). The researches show that test validity is one of significant factors that produce test anxiety. For instance, Young (1991) found that students experience anxiety if the test involves content that was not taught in class. Similarly, Horwitz and Young (1991) noted that tests in the lack of face validity led to higher anxiety and a negative attitude toward instruction.

Test anxiety is closely related to teachers' and students' attitudes and proficiency, test applications, course contents and parental expectations. Students often complain about scoring subjectivity, the lack of inter-rater and intrarater reliability, using tests for authority and punishment, the lack of information before and after the administration, negative comments before, after and during tests. In addition, the first test application of a new teacher is another reason that provokes test anxiety (Aydin, Yavuz, Yeşilyurt, 2012, p.154).

\subsection{How does the anxiety level affect the learning process?}

According to Young (1991), six potential causes of language anxiety are involved in students' language learning, which include personal and interpersonal, learner beliefs about language learning, instructor beliefs about language teaching, instructor-learner interactions, classroom procedures and language tests. As can be seen, Young (1991) identified the causes from three aspects which are the aspects of learners, teachers and instructional practice, to which Bailey's findings also complied. Foreign Language Classroom Anxiety Scale (FLCAS) is used to measure level of anxiety. This scale integrating three related components, i.e. communication apprehension, test anxiety, and fear of negative evaluation, has been reliably used by researchers to measure foreign language learners' anxiety and examine the effect of anxiety on learning in different contexts.

Furthermore, Krashen (1985) stated that high anxiety will prevent input that learners receive in the classroom from reaching the language acquisition device in his affective filter hypothesis. In addition, Horwitz (1986) asserted that language anxiety can cause students to postpone language study indefinitely or to change majors. Maclntyre and Gardner (1994) conducted a study on anxiety, involving 97 college students that learn French, concluded that compared with more relaxed learners, those with anxiety find it more difficult to express their own views and tend to underestimate their own abilities.

Another finding in Maclntyre and Gardner's (1994) study is that anxiety and learning achievement are negatively correlated in the three stages of language acquisition - input, processing and output. Moreover, there were other studies which have been conducted to find the negative correlation between anxiety and four macro aspects in language learning, specifically in speaking and listening. For example, Maclntyre and Gardner (1994) found that speaking is by far the main agent of anxiety-arousal, and that students with high anxiety perform worse than those with low anxiety. Up to now most studies have shown a negative relationship between anxiety and language achievement. In contrast, there were some other studies which found neutral and positive relationships between anxiety and second language achievement.

\section{Hypotheses}

1) All facets of Language anxiety scale (LAS) are in a statistically significant correlation with each other.

2) Facets from learning anxiety scale are in a statistically significant negative correlation with participants' English level.

3) Facets in LAS and age are not in a statistically significant correlation. 
4) There aren't statistically significant gender differences in Language anxiety scale facets.

5) The distribution of language anxiety scores of our participants does not differ statistically significant from the normal curve.

\section{Methodology}

\subsection{Participants}

Our sample was consisted of 149 students (there were three invalid cases, so in our final sample we had 146 participants/questionnaires, which will be the object of further analysis).

62 of them were males (42.47\%) and 84 were females (57.53\%). For graphical representation, see Figure 1.

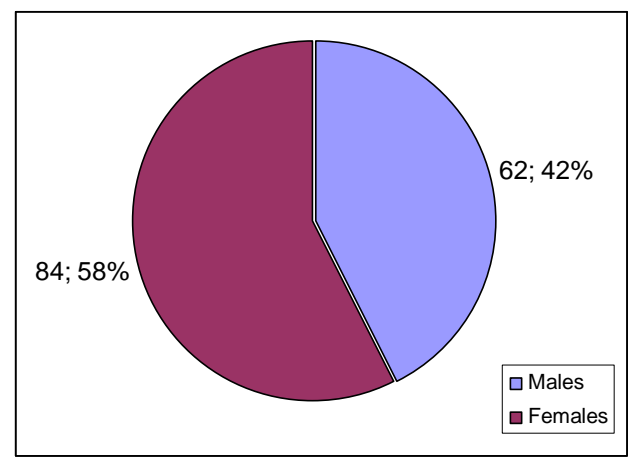

Figure 1. Gender distribution of the sample

The range of their age was from 17 to 30 years old, with average value of 18.92 years and standard deviation SD $=1.64$. According to their English level, they were represented in four categories: A - pre-intermediate, B - intermediate, C upper-intermediate and D - advanced (Figure 2).

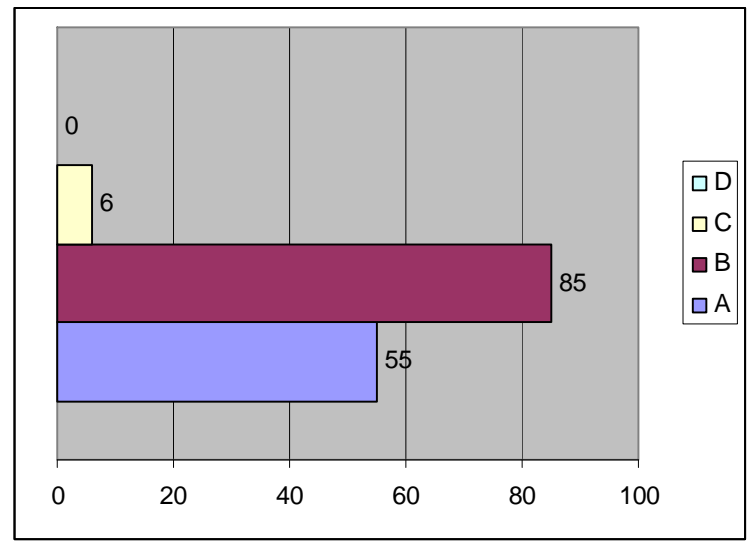

Figure 2. Distribution of sample, by English level

As we can see from Figure 2 and from our calculations, 55 participants (37.7\%) were at pre-intermediate level (A), 85 of them $(58.2 \%)$ were at imtermediate level (B), $6(4.1 \%)$ were at upper-intermediate level $(\mathrm{C})$ and nobody was at advanced level (D). 


\subsection{Instruments}

We applied Language anxiety scale (LAS) which is consisted of 22 items. Before them, there were four basic questions: name (it was optional), gender, age and level (participants could choose A - pre-intermediate, B - intermediate, C upper-intermediate and D - advanced). These main 22 items were in the form of Likert five-grade scale, where 1 means strongly disagree, 2 - disagree, 3 - neither agree nor disagree, 4 - agree and 5 - strongly agree).

First we conducted factor analysis. It was possible, because Kaiser-Meyer-Olkin measure of sampling adequacy was $\mathrm{KMO}=.807$ and Bartlett's test of sphericity shows statistically significant chi-square $\left(X^{2}(231)=1857.823, p<.001\right)$. We have chosen, by apriori criterion, three-factor solution. This has been the most interpretable solution and it explains $54.122 \%$ of data variance. We used promax rotation, so we can let our factors to be in intercorrelations. The content of our scale (questionnaire) allowed us to do that because there were similar items.

The first extracted factor was called Feeling worried because the content of its corresponding questions suggested that. Its items are: $1,2,3,5,6,7,9,10,11,12,16,20$. and 21 . Hence, it was our first subscale of LAS. Its reliability was high: $\alpha=.917(n=13)$.

The second extracted factor was named as Feeling confused and its corresponding items are: 4, 8, 13, 14. and 17. Cronbach's coefficient of internal consistency (i.e. reliability) was $\alpha=.654(n=5)$.

The last factor was called as Negative attitude towards tests, and it is represented by its three questions: 15,18 . and 19. Its reliability coefficient is high enough, despite of small number of its questions ( $a=.653, n=3$ ).

Because we threw out item no. 21, the final version of our scale has 21 items. Its reliability, expressed as Cronbach's coefficient, is $\alpha=.882$.

\subsection{Procedure}

We have made electronic version of Language anxiety scale (LAS) and applied it in the sample of students who were in their late adolescent period. It takes them about 5 minutes to complete it. It was automatically indicated the time of filling questionnaires and there was a control for double-answering from the same person. After this process, the data were automatically entered into MS Office Excel sheet, then the autor of this research transfered them to SPSS database.

\section{Results and Discussion}

First, we calculated descriptives of our data (Table 1).

Table 1. Descriptive values of Language anxiety scale

\begin{tabular}{|l|c|c|c|c|}
\hline LAS & minimum & maximum & $\mathrm{M}$ & $\mathrm{SD}$ \\
\hline $\begin{array}{l}\text { Feeling } \\
\text { worried }\end{array}$ & 17 & 65 & 43.10 & 11.44 \\
\hline $\begin{array}{l}\text { Feeling } \\
\text { confused }\end{array}$ & 5 & 24 & 11.98 & 3.89 \\
\hline $\begin{array}{l}\text { Negative attitudes } \\
\text { towards test }\end{array}$ & 4 & 15 & 10.50 & 2.75 \\
\hline $\begin{array}{l}\text { Language anxiety } \\
\text { scale (overall) }\end{array}$ & 31 & 95 & 64.00 & 14.44 \\
\hline
\end{tabular}

As we can see, the most variable facet of Language anxiety scale is "Feeling worried", which standard deviation is 11.44. The average score on this facet is $\mathrm{M}=43.10$. "Feeling confused is more variable than "Negative attitudes towards test". Its standard deviation is $s=3.89$ and arithmetic mean is $M=11.98$. Participants' average score on "Negative attitudes towadrs test" is $M=10.50$ and $s=2.75$. All 21 items of LAS, taken together, have arithmetic mean of $M=64.00$ and standard deviation which is $s=14$. 44. LAS, logically, has the largest range of results (minimum is 31 and maximum 95), which is 64 . The range for "Feeling worried" is 48 , for "Feeling confused" is 19 and for "Negative attitudes towards tests" is 11 .

In order to test our first hypothesis, we used Pearson's coefficient of correlation and we made a matrix with intercorrelations of the facets of LAS. 
Table 2. The intercorrelation matrix for three facets of Language anxiety scale

\begin{tabular}{|c|c|c|c|}
\hline Facets of LAN & Feeling worried & Feeling confused & $\begin{array}{c}\text { Negative attitudes } \\
\text { towards test }\end{array}$ \\
\hline Feeling worried & 1 & $.490 * *$ & -.034 \\
\hline Feeling confused & $.490 * *$ & 1 & .073 \\
\hline $\begin{array}{l}\text { Negative attitudes } \\
\text { towards test }\end{array}$ & -.034 & -073 & 1 \\
\hline
\end{tabular}

Table 2 shows us that only "Feeling worried" and "Feeling confused" correlate statistically significant with each other $(r=$ $.490, p<.01)$. So, "Feeling worried" isn't statistically related to "Negative attitudes towards test" $(r=-.034, p>.05)$, also, "Negative attitudes towards test" and "Feeling confused" aren't in a statistically significant correlation with each other $(r=$ $.073, p>$.05). Therefore, we can accept our first hypothesis just partially.

Because we wanted to examine is there a negative correlation between different aspects of language anxiety and level of English knowledge and skills, we also conducted correlational analysis. But, this time we used Spearman's rho coefficient of rang correlation, because the variable "level" is ordinal variable. The results are shown in Table 3.

Table 3. Correlations between facets of LAS and participants' English level

\begin{tabular}{|l|c|}
\hline LAS facets & English level \\
\hline Feeling worried & .075 \\
\hline Feeling confused &. .052 \\
\hline Negative attitudes towards test & .099 \\
\hline
\end{tabular}

*correlation coefficients are significant at level .05

**correlation coefficients are significant at level .01

None of the three facets is correlated with English level of participants: "Feeling worried" (rho $=.075, p>.05$ ), "Feeling confused" (rho $=-.052, p>.05$ ) and "Negative attitudes towards test" (rho $=.099, p>.05$ ). To conclude, our second hypothesis was rejected. Therefore, language anxiety aspects (factors and manifestations) aren't in negative (nor positive) correlations with level of English knowledge and skills.

Our fourth hypothesis was null-hypothesis and we calculated correlation coefficients in order to test it (Table 4).

Table 4. Correlations between facets of LAS and age of participants

\begin{tabular}{|l|c|}
\hline LAS facets & Age \\
\hline Feeling worried & .038 \\
\hline Feeling confused & .141 \\
\hline Negative attitudes towards test & .147 \\
\hline & *correlation coefficients are significant at level .05 \\
** correlation coefficients are significant at level .01
\end{tabular}

As we can conclude from Table 4, none of the manifestations/aspects of language anxiety is significantly correlated with participants' age: Feeling worried $(r=.038, p>.05)$, Feeling confused $(r=.141, p>.05)$ and Negative attitudes towards test $(r=.147, p>.05)$.

The previous results indicate that we can accept our third hypothesis.

We also wished to examine differences between males and females in all aspects of language anxiety. Because of that, we conducted t-test(s) for independent samples. The results are shown in Table 5. 
Table 5. Gender differences in facets of Language anxiety Scale

\begin{tabular}{|c|c|c|c|c|c|c|}
\hline Facets & $\mathrm{N}$ & $\mathrm{M}$ & SD & $\mathrm{t}$ & $\mathrm{df}$ & $\mathrm{p}$ \\
\hline Feeling worried & $\begin{array}{ll}\text { M } & 62 \\
\text { F } & 84\end{array}$ & $\begin{array}{l}39.87 \\
45.48\end{array}$ & $\begin{array}{l}13.20 \\
9.33\end{array}$ & -3.008 & 144 & .003 \\
\hline Feeling confused & $\begin{array}{ll}\text { M } & 62 \\
\text { F } & 84\end{array}$ & \begin{tabular}{|l|}
11.84 \\
12.08
\end{tabular} & $\begin{array}{l}4.29 \\
3.59\end{array}$ & -.374 & 144 & .709 \\
\hline $\begin{array}{l}\text { Negative attitudes } \\
\text { towards test }\end{array}$ & $\begin{array}{ll}\text { M } & 62 \\
\text { F } & 84\end{array}$ & $\begin{array}{l}11.23 \\
9.96\end{array}$ & $\begin{array}{l}2.75 \\
2.63\end{array}$ & 2.807 & 144 & .006 \\
\hline
\end{tabular}

We got gender difference on the subscale Feeling worried, because females have higher average result $(M=45.48)$ than males $(M=39.87)$, and this difference is statistically significant ( $(144)=-3.008, p<.01)$. In the case of Feeling confused, we haven't statistically significant difference between males and females $(t(144)=-.374, p>.05)$.

Males have higher arithmetic mean $(M=11.23)$ on Negative attitudes towards test, than females $(M=9.96)$, and this difference is statistically significant $(t(144)=2.807, p<.01)$.

The first finding is coherent with the results of research in personality psychology, because it is shown that women are less emotionally stable than males. So, they are more prone and inclinable to anxiety, worriness and similar emotional states. Furthermore, the first and the third finding suggest that we can reject the most part of our fourth hypothesis.

Finally, we examined the shape of distribution for our summative results on Language anxiety scale (LAS). For this purpose, we applied Kolmogorov-Smirnov test. It showed that distribution of scores on LAS isn't statistically different from the normal curve (Kolmogorov-Smirnov $Z=.669, p=.762$ ).

Figure 3 shows the histogram with the normal curve for overall language anxiety scores.

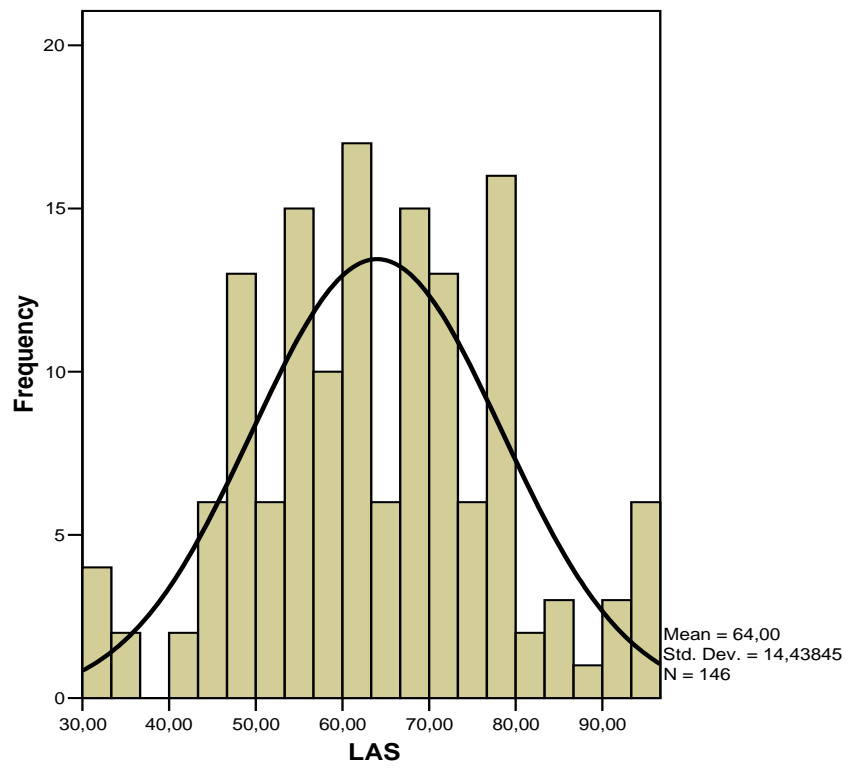

Figure 3. Histogram of results on the Language anxiety scale

Hence, our fifth hypothesis is proven ( $p$ value is greater than .05). We also can see (from Table 1 ) that, in our sample, the average result on this scale was $M=64$, which is very close to theoretical average result, which is $M=63$. Referring on the previous sentences, we can make this conclusion: LAS has very good potential to discriminate different participants based on the level of their anxiety in the classroom. In other words, it is enough variable; we have the largest number of results around the average value and left-right sided symmetry (there's similar number of results at the left and right from the central value, i. e. mean). 


\section{Conclusion}

The first finding of the study is the high exam anxiety level of Turkish EFL students. It is found that as teachers are surprized with some of the students low exam results contrast to the students' high performance in during the courses. This study shows that most of the participants have high level of exam anxiety. Most of the participants think that if they do not have exam anxiety they would have higher results. The first outcome of the study is to make an effective action plan to degrese the high exam anxiety level of Turkish EFL students.

The second finding of the study is the high negative effect of the exam results to the students' learning process. Most of the participants think that because of the low marks they had from the exams they are becoming demotivated in the class. Most of them think that if they had good marks in the exams thier learning process should be better. The second outcome of the study is taking into consideration of motivational factors caused by exam anxiety. There would be a more effective learning process if the high exam anxiety level of Turkish EFL students can be degreased.

\section{References}

Aydin, S., Yavuz, F., Yeşilyurt, S., "Test anxiety in foreign language learning", p. 145-160, 2012.

Aydogan, H., Akbarov, A., Dogan, A., Gonen, K., Tuncdemir, E., Kerla, M., "I can understand but I cannot speak: Language anxiety for oral communication", Global Challange International Journal of Linguistics, Literature and Translation, Vol: I, issue 2, ISSN 18578934.

Blau, A., "A unitary hypothesis of emotion: Anxiety, Emotions of Displeasure, and Affective Disorders", Psychoanalytic Quarterly, 24, p. 75-103, 1995.

Cao, Y., "Comparison of Two Models of Foreign Language Classroom Anxiety Scale", Philippine ESL Journal, Vol. 7, p.73-93, July 2011.

Ellis, R., "The study of second language acquisition", Oxford: Oxford University Press, 1994.

Gardner, R. C., "Social Psychology and second language learning: The role of attitudes and motivation", London: Edward Arnold, 1985.

Horwitz, E. K., "Preliminary evidence for the reliability and validity of a foreign language anxiety scale", TESOL Quarterly, 20, p. 559 564,1986

Horwitz, E. K., Horwitz, M. B., \& Cope, J., "Foreign language classroom anxiety" Modern Language Journal, 70, p. 125-132, 1986.

Krashen, S., "The Input Hypothesis", London: Longman, 1985.

Maclntyre, P. D., \& Gardner, R. C., "The subtle effects of language anxiety on cognitive processing in the second language", Language Learning, 44, p. 283-305, 1994.

Oxford, R. L., "Anxiety and the language learner. New insights. In J. Arnold (Ed.), Affect in language learning (pp.58-67)", Cambridge: Cambridge University Press, 1999.

Sarason, Irwin G., "Stress, anxiety, and cognitive interference: Reactions to tests", Journal of Personality and Social Psychology, Vol 46(4), April 1984.

Scovel, T., "The effect of affect on foreign language learning: A review of the anxiety research", Language Learning, 28, p. 129-42, 1978.

Spielberger, C., "Manuel for the state-trait anxiety inventory", Palo Alto, Calif.: Consulting Psychologists Press, 1983.

Young, D. J., "Creating a low-anxiety classroom environment: what does the language anxiety research suggest?", Modern Language Journal, 75(4), p. 426-437, 1991. 